DOI 10.37882/2223-2974.2021.05-2.09

\title{
ОЦЕНКА ВЛИЯНИЯ ПАНДЕМИИ COVID-19 НА РАЗВИТИЕ ЕВРАЗИЙСКОЙ ЭКОНОМИЧЕСКОЙ ИНТЕГРАЦИИ И ПРОМЫШЛЕННОЙ КООПЕРАЦИИ
}

\section{ASSESSMENT OF THE IMPACT OF THE COVID-19 PANDEMIC ON THE DEVELOPMENT OF THE EURASIAN ECONOMIC INTEGRATION AND INDUSTRIAL COOPERATION}

\section{Morkovkin \\ V. Popov \\ N. Gainullina}

Summary: The article discusses the main socio-economic consequences of the COVID-19 pandemic on the member states of the Eurasian Economic Union. A comparative analysis of economic indicators within the EAEU is carried out. Special attention is paid to the problems that arose during the quarantine restrictions and the measures taken to solve them in the context of the development of industrial cooperation of the EAEU member states. Further strategic steps are outlined to strengthen the integration association.

Keywords: economy, integration, EAIS, pandemic, COVID-19, socioeconomic development, common economic space, industrial cooperation.

\section{Введение}

$\Pi$ андемия, охватившая мир, внесла коррективы во все сферы привычного нам образа жизни. Первостепенной проблемой стал сам вирус и меры борьбы с ним, однако через некоторое время мировое сообщество столкнулось с новым вызовом - падением экономик большинства стран мира. В одиночку справиться со сложившейся ситуацией весьма тяжело, если не невозможно. Таким образом, роль интеграционных группировок, в том числе региональных, возросла с новой силой. Взаимодействие по вопросам функционирования экономики и бизнеса, науки и медицины, социальной сферы является необходимым условием успешного преодоления кризисного периода.

\section{Социально-экономические показатели} ЕАЭС поА влиянием панАемии

Для начала стоит вспомнить, что Договор о Евразий-

\section{Морковкин Дмитрий Евгеньевич}

К.э.н., дочент, ФГОБУВО «Финансовый университет при

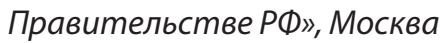

MorkovkinDE@mail.ru

Попов Владислав Русланович

Аспирант, , ЧОУ ВО «Московский университет имени С.Ю. Buтmе» (МИИТ), Москва

popovlad17@mail.ru

Гайнуллина Нонна Руслановна

ФГОБУ ВО «Финансовый университет при Правительстве

PФ», Москва

nonna.gainullina@gmail.com

Аннотация: В статье рассматриваются основные социально-экономические последствия влияния пандемии COVID-19 на страны-участницы Евразийского экономического союза). Проводится сравнительный анализ экономических показателей внутри ЕАЭС. Особое внимание уделяется проблемам, возникшим в период карантинных ограничений и мерам, принятым для их решения в контексте развития промышленной кооперации стран-участниц ЕАЭС. В результате проведенного исследования обозначены дальнейшие стратегические шаги для укрепления интеграционного экономического объединения.

Ключевые слова: экономика, интеграция, ЕАЭС, пандемия, COVID-19, социально-экономическое развитие, единое экономическое пространство, промышленная кооперация.

ском экономическом союзе ${ }^{1}$ определяет обеспечение соблюдения четырех свобод в рамках интеграции: свободы движения товаров, услуг, капитала и рабочей силы [1]. Все это в свое время увеличило трансграничную мобильность и ускорило процесс интеграции. Однако меры, касающиеся борьбы с коронавирусом, предпринятые государствами стран-участниц Евразийского экономического союза сильно ограничили данные свободы и сократили возможности межграничного взаимодействия [2].

Наблюдалось снижение основных социально-экономических показателей ${ }^{2}$, среди которых: индекс промышленного производства, грузооборот, перевозки пассажиров и оборот розничной торговли (см. рис. 1).

Так, индекс промышленно производства в январе октябре 2020 года по сравнению с аналогичным периодом 2019 года составил 97,2\%. В январе - октябре 2019 года по сравнению с тем же периодом 2018 года он был

1 "Договор о Евразийском экономическом союзе" (Подписан в г. Астане 29.05.2014) (ред. от 15.03.2018)

2 Январь-октябрь 2020 год. 


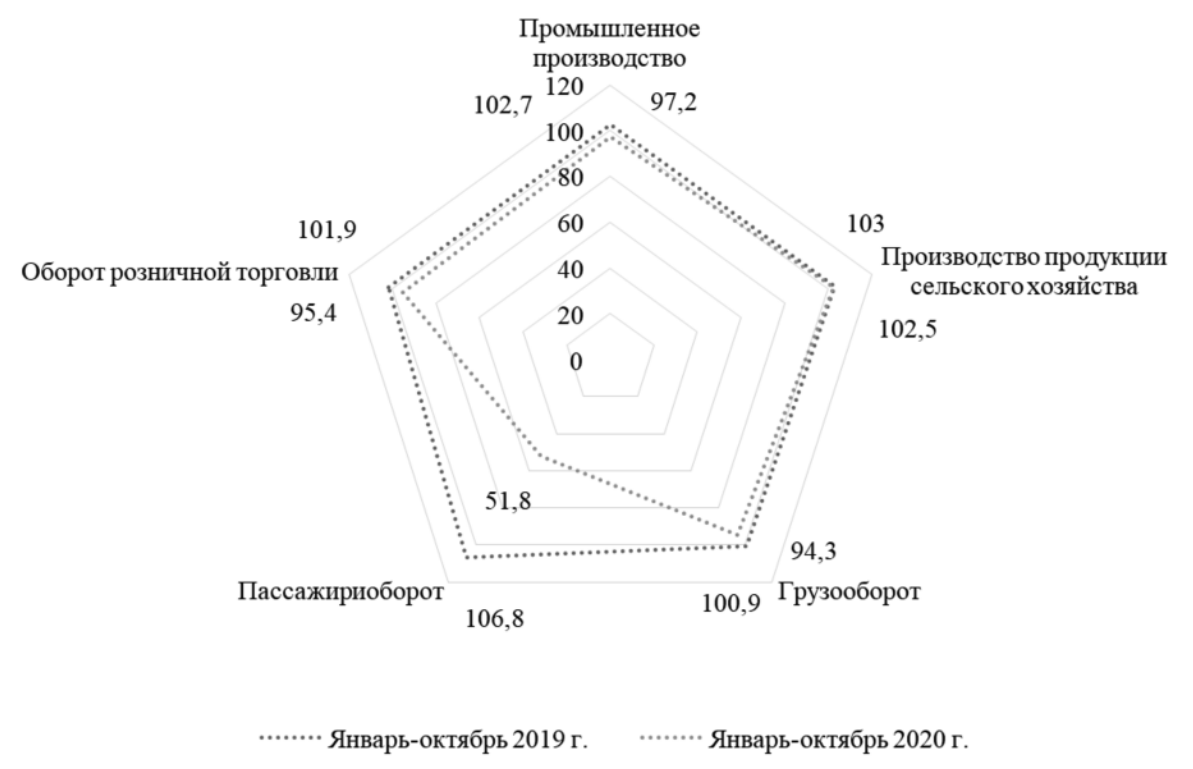

Рис. 1. Основные экономические показатели ЕАЭС (в \% к соответствующему периоду предыдущего года). Источник: составлено авторами по данным ЕЭК (Евразийская экономическая комиссия).

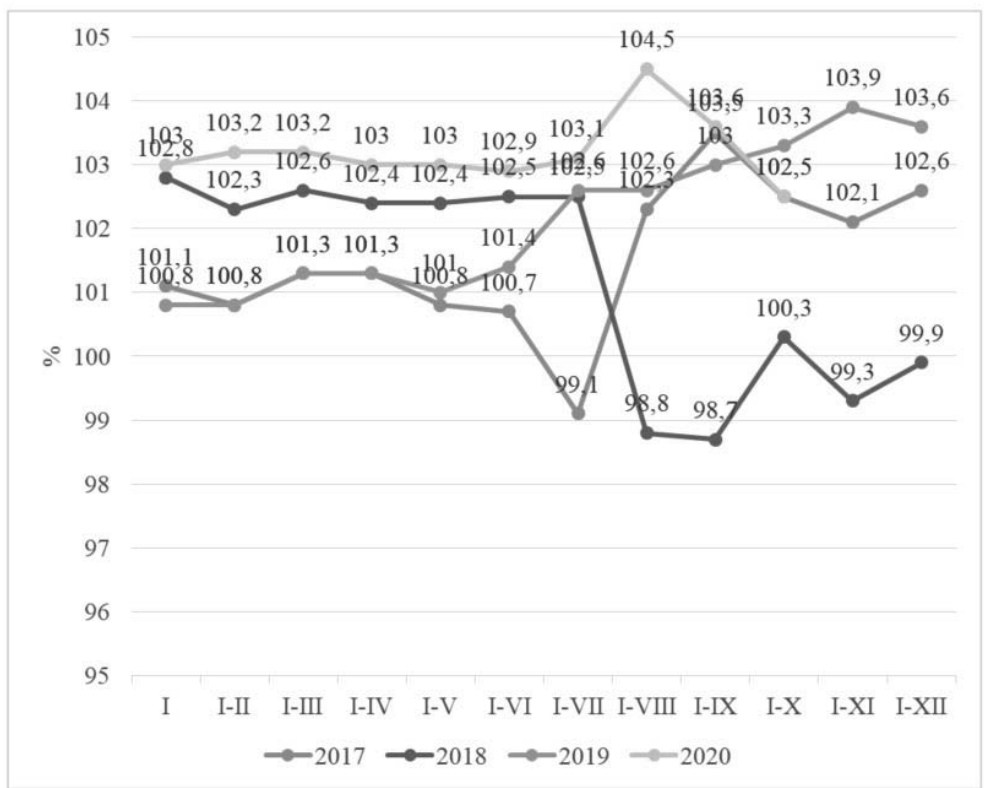

Рис. 2. Динамика производства продукции сельского хозяйства стран-участниц ЕАЭС ${ }^{4}$ (2018-2020). Источник: составлено авторами по данным ЕЭК.

равен $103,5 \%$.

Индекс оборота розничной торговли составил 95,4\% (в 2019 году по сравнению с 2018 - 102,2\%).

Индекс грузооборота равен 94,3\% (в 2019 году по сравнению с 2018 - 101,1\%).

Однако, стоит отметить рост производства продук-

Январь - октябрь 2019 год.

в \% к соответствующему периоду; в постоянных ценах

в постоянных ценах ции сельского хозяйства во всех государствах-членах ЕАЭС, он составил $102,5 \%$ к соответствующему периоду 2019 года ${ }^{3}$ (см. рис. 2) [7].

Так, производство продукции сельского хозяйства в хозяйствах всех категорий стран-участниц ЕАЭС составило 98,0 миллиардов долларов США, что выше на 2,5\%5, чем в 2019 году за тот же период. В январе - октябре 2019 года по сравнению с аналогичным периодом 2018 
Таблица 1.

Производство продукции сельского хозяйства.

\begin{tabular}{|c|c|c|c|}
\hline Страна-участница ЕАЭС & Млн. долларов США & $\begin{array}{c}\text { С \% кнварю-октябрю 2019 года (в } \\
\text { постоянных ценах) }\end{array}$ & $\begin{array}{c}\text { Январь-октябрь 2019 в \% к январю- } \\
\text { 0ктябрю 2018 года (в постоянных } \\
\text { ценах) }\end{array}$ \\
\hline Армения & 1193,3 & 100,6 & 95,7 \\
\hline Беларусь & 8444,5 & 104,6 & 102,4 \\
\hline Казахстан & 13139,8 & 105,2 & 99,6 \\
\hline Кыргызстан & 2889,9 & 100,8 & 102,6 \\
\hline Россия & 72298,9 & 101,8 & 104,1 \\
\hline
\end{tabular}

Источник: составлено авторами по данным ЕЭК.

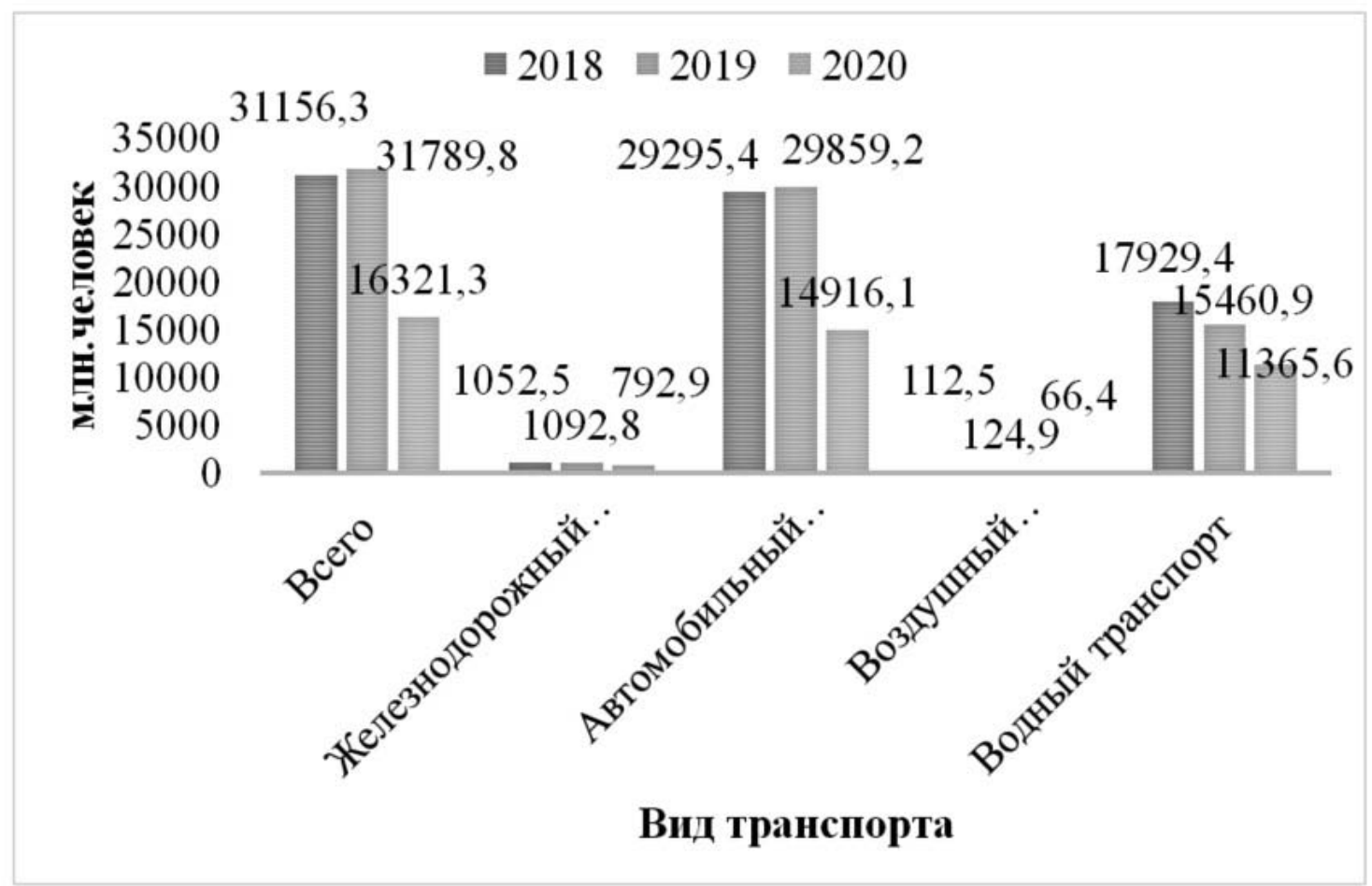

Рис. 3. Перевозки пассажиров по видам транспорта (2018-2020). Источник: составлено авторами по данным ЕЭК.

года увеличение произошло на 3,3\%. За аналогичный период увеличение в 2018 по сравнению с 2017 произошло на 0,3\%. Говоря об основных видах продукции животноводства, рост произошел в таких группах как скот и птица на убой и молоко по хозяйствам всех категорий. Самый большой рост наблюдался в Казахстане - 105,2\% к январю-октябрю 2019 года (см. таблица 1) [5][6][7].

Говоря о пассажирообороте, для большей наглядности рассмотрим объем перевозок пассажиров. Он просел глобально, что и неудивительно. Он составил 16,3 миллиарда человек и это на 43,5\% меньше, чем в 2019 году. В январе - октябре 2019 года объем перевозок пассажиров был равен 31,8 миллиардам человек, что на 2,0\% больше, чем за аналогичный период 2018 года. (см. рис. 3).

Также невозможно не рассмотреть статистику по торговле между странами-участницами ЕАЭС. Объем взаимной торговли товарами за январь - октябрь 2020 года составил 38,8 миллиардов долларов США, то есть 87,2\% к уровню аналогичного периода 2019 года (см. рис. 4).

Что касается, товарной структуры взаимной торговли стран-участниц ЕАЭС, то здесь сильных перекосов не наблюдалось. Доли остались почти неизменны. Так, наибольший удельный вес в товарной структуре зани- 


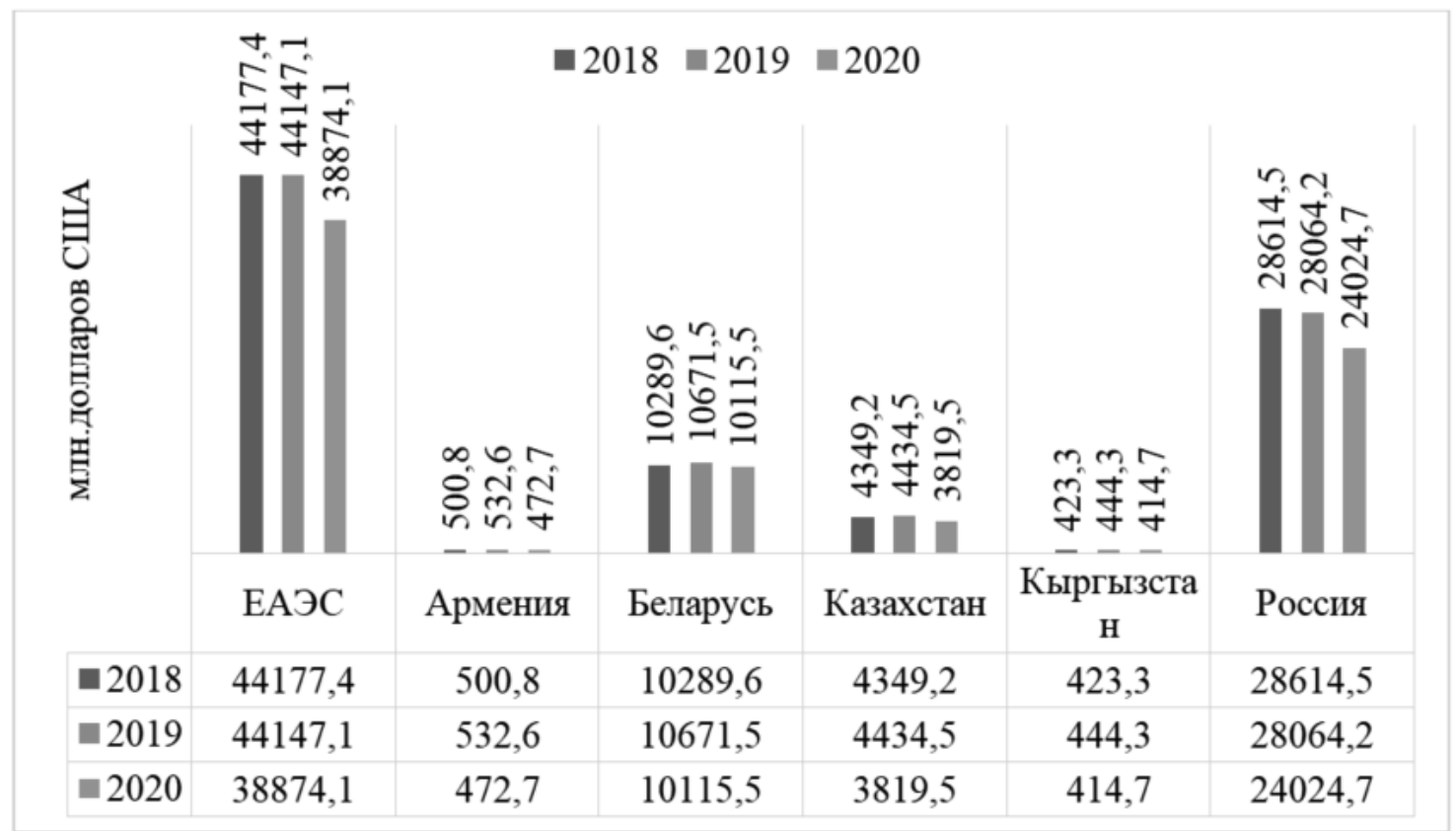

Рис. 4. Объемы экспортных поставок во взаимной торговле государств - членов ЕАЭС (2018-2020). Источник: составлено авторами по данным ЕЭК.

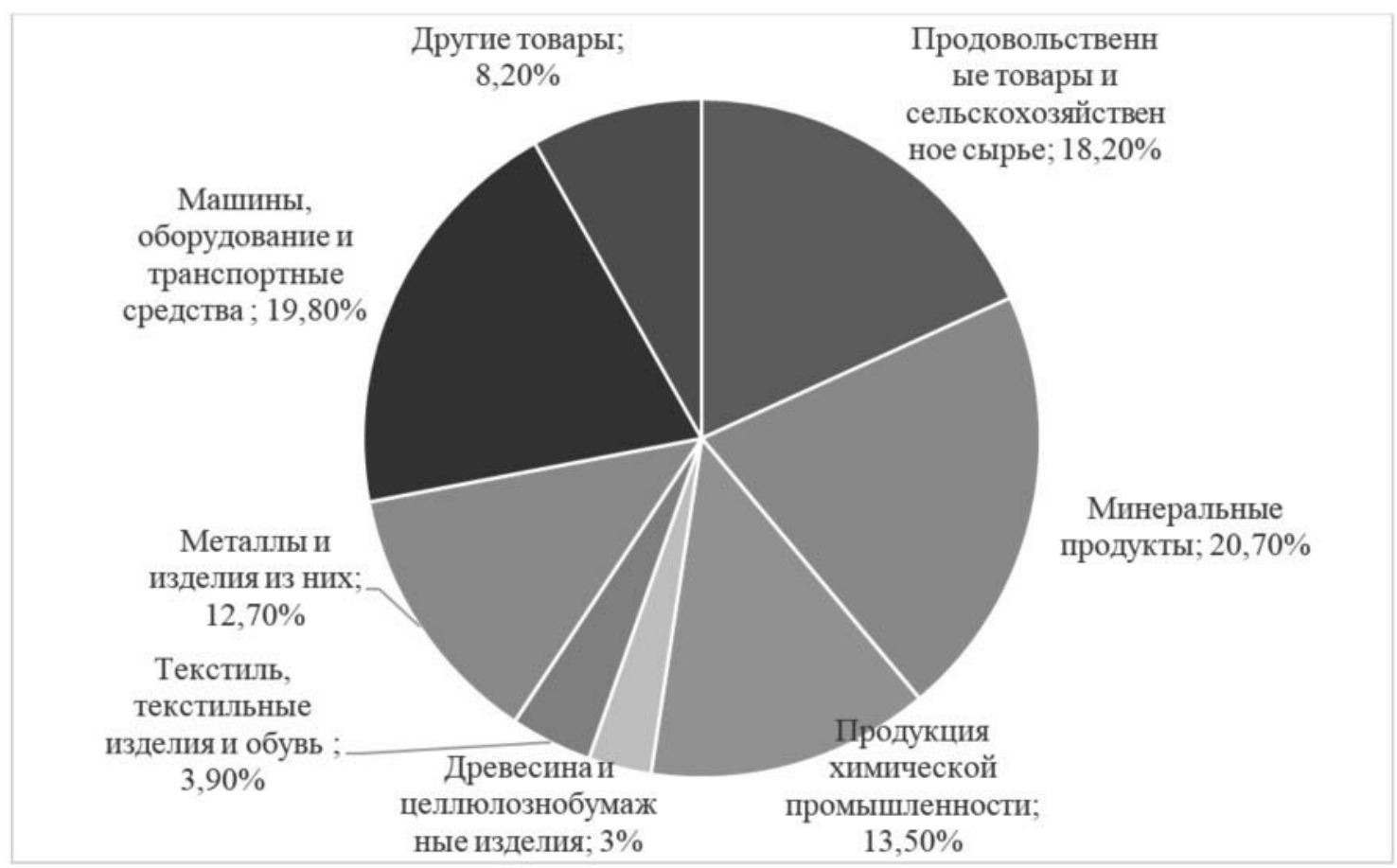

Рис. 5. Товарная структура экспорта во взаимной торговле государств - членов ЕАЭС за январь-октябрь 2020 года. Источник: составлено авторами по данным ЕЭК.

мают минеральные продукты - 20,7\%. Вторые по величине - поставки машин, оборудования и транспортных средств - 19,9\%. Далее следуют продовольственные товары и сельскохозяйственное сырье с долей 18,2\% и продукция химической промышленности - 13,6\% (см. рис. 5) [7].

\section{Основные проблемы, вызванные пандемией} и перспективы их решений

Пандемия повлияла на все страны мира без исключения. Внутри ЕАЭС она обнажила проблемы каждой страны-участницы во всех сферах экономики и общества. Каждое государство принимало ряд мер с целью защиты 
от пандемии. К сожалению, интеграционные механизмы в данной ситуации не проявили себя должным образом. Договоренности были достигнуты лишь в ряде случаев.

Сюда можно отнести оперативный запрет вывоза из стран ЕАЭС отдельных видов продовольственных товаров, расширение перечня товаров, которые освобождаются от ввозной пошлины. Также был принят Комплексный план краткосрочных и долгосрочных мероприятий в сфере санитарно-эпидемиологического благополучия и здравоохранения [3].

Главным вопросом стал вопрос эффективности и действенности объединения. В данном контексте был необходим своевременный обмен информацией, знаниями, ресурсами и медицинскими работниками. Первый шаг в данном направлении был сделан еще до пандемии, когда были созданы общие рынки лекарственных средств и медицинских изделий (с 6 мая 2017 г.).

Можно также отметить, что союз не был готов к столкновению лицом к лицу с такой неожиданной и "новой" проблемой. Ведь недавние более-менее заметные массовые заболевания обходили страны союза стороной. Из этого последовало отсутствие опыта взаимодействия в рамках пандемии. Кроме пандемии на экономику России и Казахстана повлиял и сильный обвал цен на нефть, произошедший в марте. Это произошло из-за переизбытка ее производства, а также ситуации с ОПЕК+ (Организация стран - экспортёров нефти +) [8].

Страны по-разному и в разные промежутки времени оценили угрозы пандемии, что повлекло за собой индивидуальное определение тактики борьбы. Также ситуация скорее активизировала двустороннее сотрудничество между странами, нежели коллективное взаимодействие.

Пандемия и кризис обострили ранее не решённые вопросы и показали основные пути дальнейшего развития интеграции. На деле, страны-участницы ЕАЭС оказались дальше друг от друга, чем это казалось. В первую очередь это связано с вопросом закрытия границ между участниками евразийской интеграции. Актуальным вопросом также остается тема трудовых мигрантов.

Однако, несмотря на проблемы сегодняшнего дня, ЕАЭС работает на перспективу. В декабре главы государств ЕАЭС утвердили Стратегические направлений развития евразийской экономической интеграции до 2025 года. Здесь, основное внимание уделяется развитию новых форм сотрудничества, которые бы опирались, прежде всего, на научно-техническое развитие, поддержание финансово-экономической стабильности странучастниц и эффективную занятость. Реализация данной стратегии обеспечит инновационное и инвестиционное развитие стран-участниц ЕАЭС. В ней также прописаны основные механизмы сотрудничества в тех сферах, которые не предусмотрены Договором о ЕАЭС. Это образование, здравоохранение, туризм и спорт [4].

\section{Зак^ючение}

Таким образом, в результате проведенного исследования, целесообразно подчеркнуть, что системная работа по усилению процессов промышленной кооперации и развитию экономической интеграции в ЕАЭС во время пандемии продолжалась, намеченные планы реализовались в том объеме, которые можно было позволить, учитывая все возникшие ограничения и запреты. На данном этапе разработаны и приняты программы по многовекторному международному экономическому сотрудничеству. Большое внимание уделяется развитию рынка, снятию барьеров при взаимной торговле. Дальнейшая работа по ключевым направлениям позволит разрешить возникшие трудности и развивать интеграцию по намеченном стратегическим направления.

\section{ЛИТЕРАТУРА}

1. "Договор о Евразийском экономическом союзе" (Подписан в г. Астане 29.05.2014) (ред. от 15.03.2018) [Электронный ресурс] //

СПС «Консультант - Плюс» - Режим доступа: http://www.consultant.ru/ (дата обращения:15.12.2020).

2. Меры реагирования на пандемию коронавирусной инфекции в ЕАЭС [Электронный ресурс]. - Режим доступа: http://www.eurasiancommission.org/ (дата обращения: 20.12.2020).

3. Официальный сайт Евразийского Банка Развития [Электронный ресурс]. - Режим доступа: https://eabr.org/ (дата обращения: 19.12.2020).

4. Официальный сайт Евразийской экономической комиссии [Электронный ресурс]. - Режим доступа: http://www.eurasiancommission.org// (дата обращения: 22.12.2020).

5. Об основных социально-экономических показателях ЕАЭС (январь-октябрь 2018). Аналитический обзор (5 декабря 2018) [Электронный ресурс]. Режим доступа: http://www.eurasiancommission.org/ru/act/integr_i_makroec/dep_stat/econstat/Documents/Analytics/indicators201810.pdf (дата обращения: 22.12.2020).

6. $0 б$ основных социально-экономических показателях ЕАЭС (январь-октябрь 2019). Аналитический обзор (9 декабря 2019) [Электронный ресурс]. Режим доступа: httр://www.eurasiancommission.org/ru/act/integr_i_makroec/dep_stat/econstat/Documents/Analytics/indicators201910.pdf 
(дата обращения: 22.12.2020).

7. 06 основных социально-экономических показателях ЕАЭС (январь-октябрь 2020). Аналитический обзор (8 декабря 2020) [Электронный ресурс]. Режим доступа: http://www.eurasiancommission.org/ru/act/integr_i_makroec/dep_stat/econstat/Documents/Analytics/indicators2020_10.pdf (дата обращения: 22.12.2020).

8. $0 б$ утверждении перечня секторов (подсекторов) услуг, в которых функционирует единый рынок услуг в рамках Евразийского экономического союза (Решение Высшего Евразийского экономического совета от 23 декабря 2014 года № 110) [Электронный ресурс] // ИПС «Әділет» - Режим доступа: http://adilet.zan.kz/rus (дата обращения:15.12.2020).

9. Абрамов В.Л., Алексеев П.В., Котова Н.Е., Лапенкова Н.В., Лосев А.А., Перская В.В., Ткаченко А.А., Эскиндаров М.А. Формирование устойчивых конкурентных преимуществ государств - участников Евразийского экономического союза в условиях нестабильности мировой экономики. - М.: Научные технологии, 2018. - 254 c.

10. Гнездова Ю.В., Хриптулов И.В., Лаврушин В.М. и др. Самозанятость и креативность в социально-экономическом развитии России: Коллективная монография. - М., 2019.

11. Засько В.Н., Донцова О.И. Особенности государственной политики в сфере управления инновационно-промышленными кластерами // Креативная экономика. - 2016. - № 11. - с. 1253-1262. - DOI: 10.18334/се.10.11.36989

12. Миндлин Ю.Б., Тихомиров Е.А. Организация импортозамещения в отечественном АПК на основе расширенных агропромышленных производственных цепочек // Современная наука: актуальные проблемы теории и практики. Серия "Экономика и право". -2017. - № 4. - С. $35-41$.

13. Миндлин Ю.Б. Инновационное развитие АПК в России на основе интеграционных процессов кластеризации // Современная наука: актуальные проблемы теории и практики. Серия: Экономика и право. - 2019. - № 6. - С.52-57.

14. Морковкин Д.Е., Гайнуллина Н.Р., Шманёв С.В. Формирование общего финансового рынка ЕАЭС как основа укрепления евразийской интеграции // Вестник ОрелГИЭТ. 2020. № 2 (52). С 73-79.

15. Сорокин Д.Е., Шманев С.В., Юрзинова И.Л. и др. Макроэкономическое регулирование: задачи и перспективы развития. / Монография. - Москва: КНОРуС, 2018. -336 c.

16. Толкачев С.А., Донцова 0.И., Комолов 0.0. Российская промышленность: влияние санкций и перспективы импортозамещения // Экономика, предпринимательство и право. - 2019. - № 4. - с. 271-288. - D0I: 10.18334/ерp.9.4.41512

17. Шманев С.В., Морковкин Д.Е. Макроэкономическое регулирование внешнеторговой деятельности в условиях глобализации // Вестник ОрелГИЭТ. 2017. № 3 (41). C. 88-94.

18. Цветков В.А., Дудин M.Н. Пандемия COVID-19 как угроза продовольственной и экономической безопасности страны // Экономика и управление. 2020. T. 26. № 4. DOI: 10.35854/1998-1627-2020-4-334-344

19. Эскиндаров М.А., Масленников В.В., Солянникова С.П., Морковкин Д.Е., и др. Стратегия ЦСР 2018-2024 гг.: лозунги, мифы и реальность (позиция экспертов финансового университета // Вестник Финансового университета. - 2017. - № 3(99). - с. 6-24.

20. Malyshev D. The Eurasian Economic Union: development prospects // Central Asia and the Caucasus. - 2015. vol. 16 - №2. - pp. 7-16.

21. Morkovkin D., Shmanev S., Shmaneva L. Problems and Trends in Innovative Transformation of Russian Economy and Infrastructure Development // Proceedings of the 3rd International Conference on Economics, Management, Law and Education (EMLE 2017). - 2017. - T. 32. - C. 10-13.

22. Vertakova Y.V., Ershova I.G., Plotnikov V.A. Educational system influence on knowledge economy formation // World Applied Sciences Journal. - 2013. - Vol. 2. pp. 679-683.

23. Roberts S. The Eurasian Economic Union: the geopolitics of authoritarian cooperation // Eurasian Geography and Economics. - 2017. - Vol. 58, Iss. 4. - pp. 418-441. DOl: $10.1080 / 15387216.2017 .1415763$

(c) Морковкин Дмитрий Евгеньевич (MorkovkinDE@mail.ru), Попов Владислав Русланович (popovlad17@mail.ru), Гайнуллина Нонна Руслановна (nonna.gainullina@gmail.com).

Журнал «Современная наука: актуальные проблемы теории и практики» 